\title{
Balanço aos 20: a Revista de História Regional no campo historiográfico brasileiro
}

\section{Twenty year assessment: Revista de História Regional within the Brazilian historiographic field}

\author{
Edson Armando Silva* \\ Marco Aurélio Monteiro Pereira**
}

\begin{abstract}
Resumo
Este artigo faz um balanço da trajetória da Revista de História Regional enfatizando a proposta epistemológica, as redes temáticas compostas pelos artigos publicados ao longo dos vinte anos de sua existência, as opções tecnológicas e o impacto da revista no campo historiográfico brasileiro.

Palavras-chave: "História Regional", "Revista de História Regional", "Historiografia", "Análise de Redes"
\end{abstract}

\begin{abstract}
This article reviews the history of the "Revista de História Regional" emphasizing the epistemological proposals, the thematic networks made up by the articles published during the twenty years of its existence, the technological options and the impact of the journal in the Brazilian historiographic field.
\end{abstract}

Keywords: Regional History, Revista de História Regional, Historiography, "Network Analysis"

\section{1- Lembranças de um projeto coletivo}

A Revista de História Regional (RHR) surgiu de uma conversa na viagem de retorno para Ponta Grossa, após a participação no IV Encontro Internacional de História e Computação realizado na UNESP, em Assis, em 1994.

\footnotetext{
* Doutor em História pela UFF, professor do DEHIS e do Programa de Pós-Graduação em História/UEPG. E-mail: edameister@gmail.com

${ }^{* *}$ Mestre em História pela UFPR, professor do DEHIS/UEPG. E-mail: marco.a.m.pereira@gmail.com
} 
Vivíamos um momento novo, não apenas técnica ou tecnologicamente falando, nas possibilidades de uso da informática na pesquisa histórica. As possibilidades de automatização mudavam a dinâmica de trabalho em áreas de pesquisa tradicionais como a construção de séries históricas em campos como a História Demográfica e campos de análise quantitativa em História Econômica e mesmo em História Social. Descortinavam-se, nas reuniões da Associação Brasileira de História e Computação, possibilidades impensáveis até pouco tempo antes, de tratamento informático de volumes imensos de dados estatísticos e de exploração de dados qualitativos. Ainda que no campo do gerenciamento eletrônico de documentos a tecnologia ainda não estivesse plenamente desenvolvida, abria-se um horizonte para a preservação digital de fontes escritas, e a digitalização e reconhecimento de escrita cursiva.

Mesmo que não se possa comparar as possibilidades tecnológicas da década de 1980 com os recursos contemporâneos, já apareciam nos experimentos as possibilidades de construção de redes semânticas hoje plenamente integradas nas principais tecnologias de gerenciamento de dados, mas naquele momento já em experimentação nas tecnologias em desenvolvimento, particularmente convém lembrar um aplicativo desenvolvido pelo professor Manfred Taller, à época presidente da Associação Internacional de História e Computação: o Kleio. Esses experimentos, embora hoje nos pareçam primários, colocavam no horizonte do historiador novas possibilidades de construção de pesquisa documental, com a utilização do computador e os primórdios do que hoje são as redes de significado.

Dentre as várias considerações feitas, a que permaneceu entre nós como uma ideia a ser desenvolvida foi a proposta de criarmos uma revista acadêmica on-line, acessível a todos pela internet, para socializar, ampliar o raio de alcance e socializar a produção historiográfica na internet.

$\mathrm{Na}$ época esta proposta parecia algo fora de lugar, com a internet ainda dando seus primeiros passos nas tecnologias de produção e armazenamento de publicações on-line. A linguagem mais utilizada para programar era o HTML 2.0 e os recursos de formatação, indexação e compartilhamento eram ainda bastante incipientes para a introdução de uma publicação científica na rede.

Além disso, havia um sensível um grau de desconfiança na comunidade dos historiadores com as possibilidades de utilização de computadores na produção historiográfica, desconfiança que aumentava quando o assunto era a possibilidade de publicações on-line na área de História.

Rapidamente, porém, a ideia de uma revista on-line foi tomando corpo e se articulando, estimulada pelo acesso ao, na época, incipiente site da 
Universidade Estadual de Ponta Grossa (UEPG), e com apoio do Departamento de História (DEHIS) da instituição. O processo de definição de sua abrangência, a ser tratado abaixo com mais vagar, considerou algumas questões epistemológicas que estavam presentes naquela conjuntura, um novo momento de renovação e abertura do DEHIS/UEPG para a construção de identidades temáticas e epistemológicas de campos e objetos.

Após várias discussões, definimos o campo da História Regional, epistemologicamente posto, como locus que compreendia praticamente a totalidade das pesquisas propostas pelos docentes do Departamento. Definido o campo, o nome Revista de História Regional surgiu naturalmente e foi construído o projeto, com Estatuto, Regimento e a composição dos Conselhos Editorial e de Consultores, que já surgiram respeitando as restrições de endogenia e que receberam a adesão de historiadores de algumas das principais universidades brasileiras.

A RHR optou por uma periodicidade sazonal, com a publicação de duas edições por ano, verão e inverno. Foi definida, também, devido principalmente a questões de reconhecimento e valoração de um projeto editorial acadêmico on-line na internet, a opção por uma dupla editoração, em mídia impressa e on-line. Como considerávamos, entretanto, cada um dos meios de divulgação como sendo uma dimensão do mesmo veículo, nunca solicitamos o segundo ISSN quando isso se mostrou a orientação geral com o surgimento de outros veículos na internet. Neste momento a RHR constrói um posicionamento diferencial em relação à quase totalidade das publicações acadêmicas vinculadas na internet à época, fazendo a opção pelo livre acesso ao conteúdo integral, sem ônus à consulta aos seus conteúdos, citada a fonte.

Com a aprovação do Projeto da RHR nos trâmites necessários foi aberta, no final de 1995, a chamada para o primeiro número, com a seleção de sete artigos, de pesquisadores ligados à UFF, UEPG e UFPR. Assim veio à luz, em meados de 1996, a primeira edição da RHR, ainda composta artesanalmente, com a diagramação feita em HTML para versão on-line e em processador de texto para a versão impressa.

A RHR surge, no âmbito da UEPG, como uma das primeiras publicações científicas que atendiam a critérios hoje consagrados, como avaliação por pares "duplo cego", exigência de originalidade e critérios de normalização. Esse pioneirismo acabou por trazer, no início, alguns problemas para as edições subsequentes, pela falta de uma cultura institucional, por questões ligadas à política universitária ou ainda pela crônica falta de recursos institucionais para viabilizar as edições impressas. 
Apesar das dificuldades iniciais, a RHR paulatinamente se consolidou institucionalmente em sua abrangência de recepção e legitimidade, aferível pela distribuição geográfica e pelo impacto dos seus artigos na produção historiográfica brasileira.

\section{Perspectivas epistemológicas}

No editorial do primeiro número da revista, sua proposta é definida como "um canal de veiculação de trabalhos que tenham enquadramento dentro do campo de 'História e Regiões' espacial e epistemologicamente posto" ${ }^{1}$. Em seguida, o texto procura distinguir entre a proposta da revista e a compreensão corrente de história regional, associada à naturalização da demarcação de fronteiras políticas, ao afirmar que "Região aqui pretende ser a definição de espaços historiográficos específicos, em contraponto a uma tendência universalizante, a-histórica e a-espacial em voga em algumas áreas das ciências sociais".

Passados mais de vinte anos a proposta continua válida, e deve ser reafirmada aqui. A proposta epistemológica da RHR teve como princípio a indissociabilidade entre tempo e espaço na análise da realidade social. Tanto o tempo como o espaço são compreendidos como construções sociais e, portanto, se fazem por meio de processos específicos que, ao serem consideradas na análise da História, ampliam as dimensões em análise, permitindo a superação de uma visão universalizante e naturalizada.

Lançar esta proposta epistemológica foi um desafio. O periódico científico criado em 1996 tinha como objetivo a ressignificação das formas tradicionais de se pensar a História Regional como uma história local, restrita temporal e espacialmente, de menor valor científico em relação às produções intelectuais que abordavam grandes períodos temporais e amplos recortes espaciais. Tal perspectiva científica implicou na abertura de novos horizontes políticos, a partir de debates com a comunidade científica de História e também a abertura do campo de saber historiográfico, para valorizar novos sujeitos históricos.

Esta tarefa não foi algo simples pois, devido ao peso da tradição epistemológica sobre a história regional. Durante vários momentos, a revista sofreu uma interpretação distorcida de sua intencionalidade na produção acadêmica. A concepção e a abrangência do termo região, um dos conceitos que sustentam a proposta epistemológica da revista, passaram por várias transformações ao

${ }^{1}$ RHR, Editorial, Revista de História Regional, v. 1, n. 1, 1996. 
longo do tempo, notadamente na ciência geográfica, conforme aponta Meri Lourdes Bezzi² em seu artigo.

Paulo Cesar da Costa Gomes ${ }^{3}$ também descreve em seu texto alguns importantes momentos históricos no embate científico em torno do conceito de região. Logicamente não temos aqui a pretensão de realizar uma análise historiográfica do conceito, mas evidenciar os momentos chave das disputas em torno de ideias hegemônicas sobre região e as suas principais transformações conceituais. Segundo Gomes, as transformações da sociedade exigem uma reflexão permanente em torno da capacidade compreensiva que determinado conceito adquire e, certamente, as transformações das relações espaciais nos processos de globalização provocou mudanças de posturas por parte dos estudiosos voltados às perspectivas espaciais.

Roberto Lobato Corrêa ${ }^{4}$, participante do conselho da RHR deste 1998 e autor de acuradas observações a cada novo número, afirmava que o conceito de região possui uma forte tradição de ser concebido como uma área delimitada de um todo espacial, um território demarcado por um conjunto de coordenadas geográficas, ou ainda uma determinada área de gestão político-administrativa do Estado. Esses foram os usos mais comuns do conceito, que acabaram se popularizando, inclusive, no senso comum. O termo região é usualmente empregado como referência a uma área, que possui determinadas características de homogeneidade interna e diferenciação externa, para determinar seus limites.

A influência da análise marxista em torno do conceito de região trouxe a ideia de que o capital era o elemento fundamental de organização das diferenciações espaciais e que constituía, portanto, suas regiões de produção, conforme argumenta Milton Santos ${ }^{5}$. Assim, a região passou a ter um atributo de descontinuidade espacial, podendo ser também constituída em redes de relações, que aprofundavam as diferenças entre áreas, feitas para sustentar a organização da produção capitalista e a reprodução ampliada do capital.

\footnotetext{
${ }^{2}$ BEZZI, Meri Lourdes, Região: desafios e embates contemporâneos, SEI-Superintendência de Estudos Econômicos e Sociais da Bahia.(Org.). Desigualdades Regionais-Série Estudos e Pesquisas. Salvador: Bigraf, v. 1, p. 39-87, 2004.

${ }^{3}$ GOMES, Paulo Cesar da Costa. O conceito de região e sua discussão, Geografia: conceitos e temas. Rio de Janeiro: Bertrand Brasil, p. 49-76, 1995.

${ }^{4}$ CORREA, R. Lobato. Região e organização espacial, [s.l.: s.n.], 1991.

${ }_{5}^{5}$ SANTOS, Milton. Técnica, espaço, tempo: globalização e meio técnico-científico informacional, [s.1.]: Hucitec, 1996.
} 
Isso gera um verdadeiro mosaico de regiões que são exploradas e outras que captam os frutos da acumulação'.

A pertinência da região como um importante conceito para análise da sociedade contemporânea foi defendida por Rogério Haesbaert ${ }^{7}$, também conselheiro da RHR a partir de 2000. Segundo ele, embora algumas ideias sobre a região estejam superadas em função do processo de globalização, a tarefa do cientista é questionar o conceito e redefini-lo sob outra ótica. O entendimento tradicional de região como formada por áreas contínuas e demarcadas deve ser reelaborado na medida em que o processo de fragmentação espacial ocorre pelos processos de seletividade do capital mundial. Ao mesmo tempo, há um reforço de identidades culturais que resistem à globalização. Nos anos 1990, portanto, a discussão sobre região comporta o debate em torno da relação entre o global e o local, trazendo determinadas expressões para o debate como o 'globalmente local' ou 'localismos globalizados', como propõe Nigel Thrift".

O desenvolvimento da História Regional foi influenciada pelo movimento das interpretações do conceito de região. O historiador Aldieris Braz Amorim Caprini ${ }^{9}$, ao analisar a prática de pesquisadores no campo da História Regional, faz o alerta de que tais pesquisas são constantemente questionadas porque elas se baseiam num recorte espacial. A afirmação do recorte espacial nas pesquisas de História Regional, segundo as críticas, são desnecessárias, já que toda pesquisa refere-se a um espaço determinado.

Este argumento expressa a forma como grande parte dos historiadores pensa a História Regional, e é justamente nesse debate que a Revista de História Regional intervém. Não nos parece suficiente o mero reconhecimento do "recorte espacial" da pesquisa histórica como definidor de região. Tratase, sim, de perceber os processos sociais que produzem o espaço e como o conceito de "região", ao incorporar na análise a perspectiva relacional (uma região somente se define como região na sua relação com outras), revela os mecanismos de produção e reprodução de desigualdades espaciais. Essa abordagem, naturalmente, não se limita aos aspectos políticos ou econômicos, mas também às construções culturais, identitárias e simbólicas que nos

\footnotetext{
${ }^{6}$ MASSEY, Doreen B. Spatial divisions of labor: Social structures and the geography of production, Nova York: Routledge, 1984.

${ }^{7}$ HAESBAERT, Rogério. Região, diversidade territorial e globalização, Geographia, v. 1, n. 1, p. 15-39, 2009. ${ }^{8}$ THRIFT, Nigel. Visando o âmago da região. GREGORY, D.; MARTIN, R.; SMITH, G. Geografia humana: sociedade, espaço e ciência social. Rio de Janeiro: Zahar, p. 215-247, 1996.

${ }^{9}$ CAPRINI, Aldieris Braz Amorim. Pesquisa em História regional: aspectos conceituais e metodológicos, III Simpósio ILB, v. 12, p. 13, 2010.
} 
constituem enquanto sociedade. A própria opção tecnológica pela internet significa um desafio à hierarquização, naturalizada na produção acadêmica, que cria regiões centrais e periféricas.

Ora, a perspectiva regional se tornou possível justamente porque o olhar de um grupo de pesquisadores, no processo de renovação departamental e em busca de sua identidade de pesquisa, percebeu sua posicionalidade no campo historiográfico brasileiro e buscou instrumentos para questionar a hierarquização vigente. Os lugares geográficos de enunciação científica e a hierarquização regional que potencializam o espraiamento dos discursos científicos hegemônicos foram desafiados pelos conceitos e pela forma que a RHR foi operacionalizada, optando pela divulgação sem ônus do texto integral dos trabalhos pela internet. É interessante observar que há uma espacialidade de proposições epistemológicas históricas e certamente não foi por acaso que a Revista de História Regional surgiu numa universidade do interior.

Mesmo considerando a operacionalização inovadora da RHR no mundo acadêmico brasileiro nos anos 1990, o mais importante aqui é marcar o tensionamento que o periódico passou a promover no sentido conceitual e metodológico da produção científica histórica. Quando Caprini ${ }^{10}$ alerta para o fato de que os críticos da História Regional sustentam a ideia de que não há necessidade de uma história regional, já que toda pesquisa histórica tem como base um recorte espacial, o que fizemos foi chamar a atenção sobre a forma como esses críticos construíram a sua compreensão sobre região como um recorte aonde o espaço está reduzido a sua dimensão topográfica.

O conceito de região apropriado pela historiografia esteve atrelado à ideia de um espaço definido e demarcado, concebido como receptáculo onde as relações sociais aconteciam. A região aparecia, assim, apenas como um substrato fixo e imóvel. Desta forma, a produção das pesquisas com base em história regional era aquela que se atinha à formação de identidades no interior de uma determinada área com fronteiras e limites estabelecidos. Nessa perspectiva de região há uma separação entre processos históricos e espacialidades, reduzindo as espacialidades à mera ideia de localização topográfica, onde os processos históricos se desenvolviam.

As críticas sobre a produção da história regional pautada pela ideia da delimitação espacial fixa talvez tivessem alguma razão de ser, na medida em que os recortes espaciais, o local em si, eram considerados apenas cenários que suportavam as relações sociais. Na maior parte das vezes, essas abordagens

${ }^{10}$ Ibidem. 
históricas eram realizadas por intelectuais afetivamente ligados ou moradores de determinadas regiões. Assim, nessa produção científica, normalmente localizada longe dos centros de produção historiográfica nacional e internacional, a História Regional foi caracterizada como um gênero de importância secundária, reproduzindo na produção acadêmica uma hierarquização regional semelhante àquela produzida pelas relações políticas e econômicas.

A proposta epistemológica da RHR visava superar as ideias simplificadoras ou simplistas de região, ao mesmo tempo em que tinha como objetivo se inserir como sujeito da produção de conhecimento, denunciando as formas de hierarquização espacial da produção científica historiográfica no Brasil. A linha editorial da revista avançou na superação da ideia de região como sendo apenas um espaço topográfico e na ruptura com a persistente hierarquização entre as análises macro e micro, arraigadas nas concepções historiográficas.

As transformações da ideia de região, que trazem o espaço como elemento ativo e indissociável do tempo na compreensão das relações sociais, debatidas em outras áreas de produção científica, foram também incorporadas na concepção da RHR, incluindo a discussão da escala. A realidade social não está inerentemente compartimentada de forma hierárquica, como sendo ontologicamente global, nacional ou regional. A escala é uma construção social, que se naturalizou como um recurso metodológico na comunidade de cientistas, para organizar o mundo e, se num primeiro momento, ela se confundiu com a ideia de região fixa ou área delimitada, agora, no contexto da criação da RHR, a escala é considerada de maneira mais fluida, tal como apontado por Smith ${ }^{11}$. Embora escalas particulares possam ser construídas e fixadas em determinado tempo e espaço, não se deve supor que elas sejam fixas ou imutáveis. Além disso, nessa concepção, estava posta a produção relacional de região, que contemplaria as diferentes escalas, trazendo a conexão entre o local e o global.

Como não existe região em si, pois ela é produzida socialmente, assim como ocorre com a escala, os fenômenos históricos possuem como componente fundamental o espaço, entendido como algo vivo, relacional e em permanente construção e desconstrução. Com esta concepção de região, como construída socialmente, a RHR rompeu com a ideia de um espaço receptáculo, enfatizando um conceito de um espaço que se torna um dos elementos fundamentais para compreender as relações sociais específicas, escapando das

${ }^{11}$ SMITH, Neil. Homeless/global: Scaling. Places, in: Mapping the Futures: Local Cultures, Global Change, London, UK: Routledge, 1993, p. 87-119. 
metanarrativas universalizantes que homogeneizavam fatos e processos históricos, para toda e qualquer parte do globo a partir das narrativas hegemônicas.

A escala, portanto, é uma construção que o pesquisador estabelece para responder às questões formuladas sobre determinados fenômenos. Assim novas interpretações históricas podem surgir e certamente novos atores sociais, invisibilizados por narrativas estabelecidas em escalas mais amplas, também ganham visibilidade. Na perspectiva epistemológica da Revista de História Regional o conceito de região remete a uma construção relacional e aberta, que evidencia a noção de uma espacialidade múltipla numa mesma ou em múltiplas dinâmicas temporais. As relações sociais que produzem diferentes regiões, portanto, podem ser de inúmeras naturezas, econômicas, políticas, culturais. As diferentes regiões, conformadas pelas relações sociais de diferentes naturezas, podem conviver harmonicamente ou em tensionamentos constantes. Podem se estabelecer em conflitos, hegemonias e hierarquias. Assim, a RHR rompeu com a ideia de "área", na qual a história se desenvolve para associar espaço e tempo nos fenômenos históricos. Os supostos críticos ao desenvolvimento da História Regional, apontados por Caprini ${ }^{12}$, já não podem argumentar que o espaço era algo dispensável na análise dos fenômenos históricos, já que a história sempre se dá num espaço. Em nossa concepção o espaço é elemento fundamental da análise histórica.

Mignolo ${ }^{13}$ é um crítico às metanarrativas produzidas por pesquisadores que possuem o ponto de vista do centro da produção de saber. Segundo ele, é preciso pensar na simultaneidade de lugares de produção de conhecimento, e a proposta epistemológica da RHR nos anos 1990 é a conquista de um lugar próprio de enunciação de saber, que produz uma caminhada conceitual sobre a relação entre tempo e espaço. Para o grupo de pesquisadores que criaram e alimentaram a RHR durante esses 20 anos de existência, há uma simultaneidade de lugares na formação das regiões, e a abordagem regional permite uma alternativa analítica às narrativas universalizantes, que explicam a dinâmica histórica a partir dos fenômenos endógenos das regiões centrais como um movimento que parte do centro e atinge as periferias com relativo atraso. Além disso, a revista desnaturalizou os tradicionais sentidos regionais, abrindo a possibilidade para pensar e questionar os seus processos de criação. Essa abordagem permite revelar as forças que agiram no estabelecimento de determinados domínios, reconhecer a existência de outros grupos, derrotados

\footnotetext{
${ }^{12}$ CAPRINI, Pesquisa em História regional: aspectos conceituais e metodológicos.

${ }^{13}$ MIGNOLO, Walter. Local histories/global designs: Coloniality, subaltern knowledges, and border thinking, [s.l.]: Princeton University Press, 1999.
} 
ou periféricos, de suas regionalidades alternativas, bem como o papel da linguagem na naturalização de determinados sentidos.

\section{A dinâmica cotidiana da construção do campo, ou como o fazer cotidiano de chamadas, seleção e edição realiza a perspectiva epistemológica}

Depois de 20 anos e bem mais de trezentos trabalhos publicados, versando sobre os mais diferentes temas a partir de diferentes perspectivas teóricos, é um desafio fazer um balanço verificando se a proposta epistemológica da revista se concretizou no seu cotidiano. Para enfrentar este desafio, submetemos o conjunto dos metadados dos artigos publicados às técnicas de análise de redes sociais. Esta metodologia toma a realidade em sua dimensão relacional para revelar sua estrutura, centros, periferias e agrupamentos em comunidades. Para aplicar essa metodologia à produção acadêmica publicada na RHR, consideramos a relação tema-autor que produz uma rede dual e projetamos essas relações em uma rede one-mode tema-tema. Uma descrição pormenorizada da metodologia pode ser vista no artigo Ofício, Engenho e Arte: inspiração e técnica na análise de dados qualitativos ${ }^{14}$, que aplica as técnicas de análise de rede na interpretação de textos.

O importante aqui é compreender que, para a construção de uma topologia temática a partir da produção acadêmica publicada na revista, estabelecemos uma relação (que na metodologia de análise de redes chamamos "aresta") entre os temas ou palavras chaves pertencentes a um trabalho de um autor específico, e atribuímos um peso maior aos temas (chamados na análise de redes de "nós") que aparecem nos trabalhos de um número maior de autores. Estas relações produzem uma rede que revela a topologia da produção acadêmica divulgada pela revista, como passamos a analisar. 0 exercício a seguir apresenta inicialmente o grafo que resultou da relação entre todo o conjunto de temas publicados na revista:

\footnotetext{
${ }^{14}$ SILVA, Edson Armando; SILVA, Joseli Maria. Ofício, Engenho e Arte: inspiração e técnica na análise de dados qualitativos. DOI: 10.5212/Rlagg.v.7.i1.0009, Revista Latino-Americana de Geografia e Gênero, v. 7, n. 1, p. 132-154, 2016.
} 
Grafo 1: Rede de temas publicados

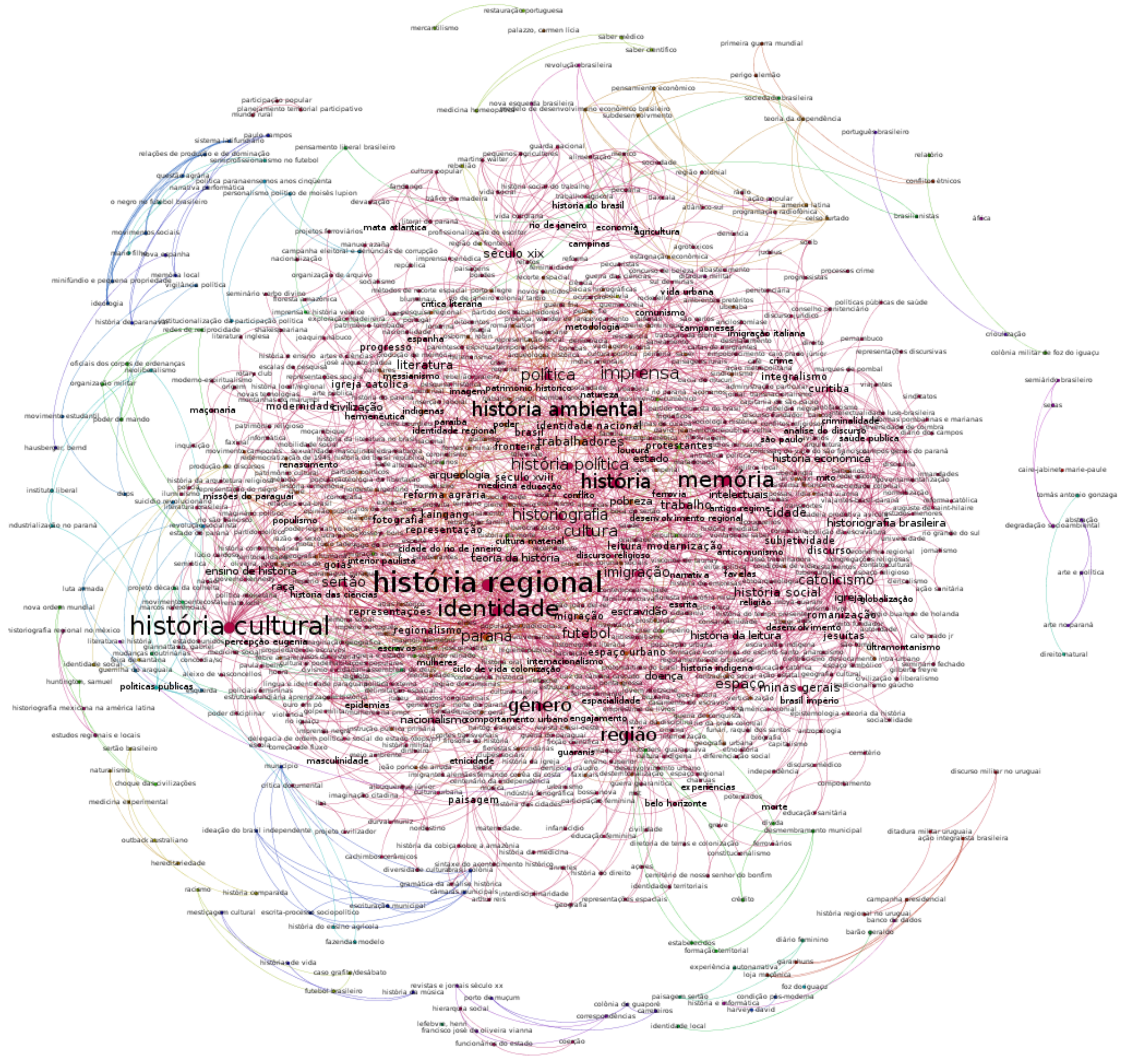




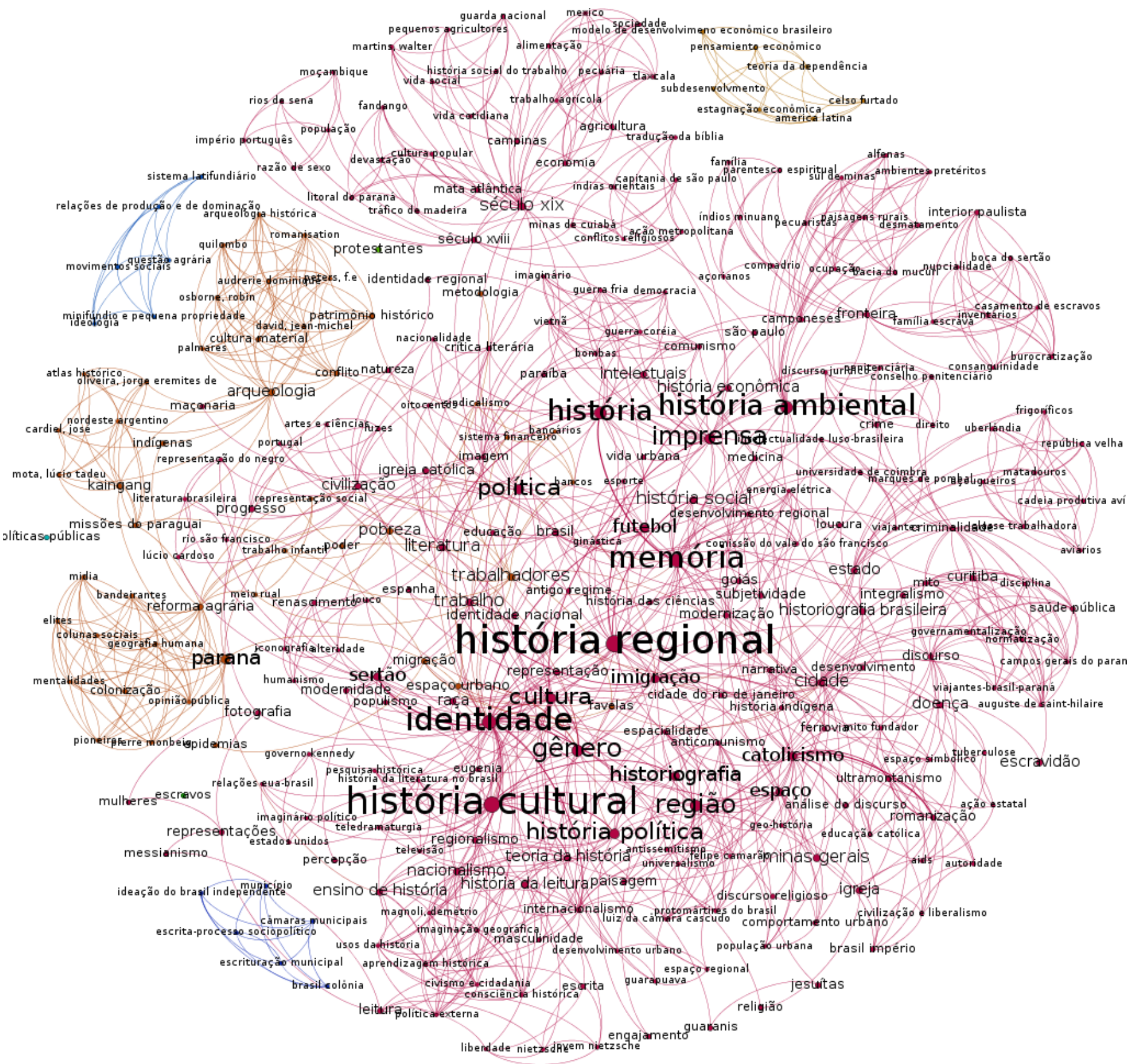


Como se pode observar, trata-se de uma rede complexa, com diversas sub-redes e comunidades específicas. Com 785 temas e 2138 relacionamentos (temas que foram tratados por um conjunto mais amplo de autores) já se pode perceber as principais centralidades, mas o tamanho e a complexidade da rede dificultam a percepção de todos os detalhes significativos na produção temática da revista. Para explorar melhor os principais aspectos da rede, faremos na sequência, diversos procedimentos de filtragem e recortes para destacar os elementos que queremos aprofundar nesta análise.

Para destacar os temas mais significativos utilizamos um filtro com os temas que apresentaram mais de 5 relacionamentos, isto é, foram citados em mais de cinco artigos. O tema "religião", por exemplo, foi trabalhado em nove artigos publicados na revista ao longo do período estudado, como se pode observar na tabela abaixo:

Tabela 1: Artigos que trataram o tema "religião"

continua

\begin{tabular}{|c|c|c|c|}
\hline Ano & Autor & Título & URL \\
\hline 1998 & Mata, Sérgio Ricardo da & $\begin{array}{l}\text { JUC E MMC: polaridade político- } \\
\text { religiosa em Belo Horizonte }\end{array}$ & $\begin{array}{l}\text { http://www.revistas2.uepg.br/ } \\
\text { index.php/rhr/article/view/2053 }\end{array}$ \\
\hline 2001 & $\begin{array}{l}\text { Sahr, Wolf Dietrich Gustav } \\
\text { Johannes }\end{array}$ & $\begin{array}{l}\text { Religion and Scientificism in } \\
\text { Brazil; Towards a Regional } \\
\text { Geography of Knowledge - a } \\
\text { Geographical Essay }\end{array}$ & $\begin{array}{l}\text { http://www.revistas2.uepg.br/ } \\
\text { index.php/rhr/article/view/2131 }\end{array}$ \\
\hline 2006 & $\begin{array}{l}\text { Zulian, Rosângela Wosiack; } \\
\text { Pereira, Denise }\end{array}$ & $\begin{array}{l}\text { Ponta Grossa: Rumo aos } \\
\text { pressupostos da Romanização }\end{array}$ & $\begin{array}{l}\text { http://revistas2.uepg.br/index. } \\
\text { php/rhr/article/view/2231 }\end{array}$ \\
\hline 2011 & Silva, Marcos José Diniz & $\begin{array}{l}\text { Rotary Club, Maçonaria e Igreja } \\
\text { Católica: "serviço social" e } \\
\text { polêmica religiosa no Ceará nos } \\
\text { anos de } 1930\end{array}$ & $\begin{array}{l}\text { http://revistas2.uepg.br/index. } \\
\mathrm{php} / \mathrm{rhr} / \text { article/view/2390 }\end{array}$ \\
\hline 2013 & Pires, Tiago & $\begin{array}{l}\text { O Cura d'Ars e a representação } \\
\text { do pastor das almas (1786-1859) }\end{array}$ & $\begin{array}{l}\text { http://www.revistas2.uepg.br/ } \\
\text { index.php/rhr/article/view/5458 }\end{array}$ \\
\hline 2013 & $\begin{array}{l}\text { Martinez, Cláudia Eliane P. } \\
\text { Marques }\end{array}$ & $\begin{array}{l}\text { Patrimônio cultural religioso } \\
\text { no Paraná: O corpo e as duas } \\
\text { "cabeças" da Igreja de São } \\
\text { Sebastião de Porto de Cima } \\
\text { (séculos XVIII ao XX) }\end{array}$ & $\begin{array}{l}\text { http://www.revistas2.uepg.br/ } \\
\text { index.php/rhr/article/view/5400 }\end{array}$ \\
\hline 2013 & $\begin{array}{l}\text { Fernandes, Luis Henrique } \\
\text { Menezes }\end{array}$ & $\begin{array}{l}\text { A literatura religiosa polemista } \\
\text { nas Índias Orientais seiscentistas } \\
\text { e a elaboração da primeira } \\
\text { tradução regular da Bíblia em } \\
\text { língua portuguesa (1642-1694) }\end{array}$ & $\begin{array}{l}\text { http://www.revistas2.uepg.br/ } \\
\text { index.php/rhr/article/view/5510 }\end{array}$ \\
\hline
\end{tabular}


Tabela 1: Artigos que trataram o tema "religião"

conclusão

\begin{tabular}{|c|c|c|c|}
\hline Ano & Autor & Título & URL \\
\hline 2013 & Benatte, Antonio Paulo & $\begin{array}{l}\text { Teologia da libertação: } \\
\text { história crítica de um discurso } \\
\text { intelectual-religioso }\end{array}$ & $\begin{array}{l}\text { http://www.revistas2.uepg.br/ } \\
\text { index.php/rhr/article/view/5569 }\end{array}$ \\
\hline 2014 & Rosa, Teresa da Fonseca & $\begin{array}{l}\text { O Iluminismo e a expulsão dos } \\
\text { jesuítas do Império Português; as } \\
\text { reformas pombalinas e o plano } \\
\text { de estudos menores }\end{array}$ & $\begin{array}{l}\text { http://www.revistas2.uepg.br/ } \\
\text { index.php/rhr/article/view/7091 }\end{array}$ \\
\hline
\end{tabular}

Para se entender a construção da rede, propõe-se levar em consideração que cada um dos artigos acima relacionados tratou especificamente do tema "religião", que na rede ganhou então o grau 9 (por ter sido tratado em nove artigos). Entretanto cada um desses artigos tratou do tema relacionando-o a outros como a JUC, a Romanização em Ponta Grossa, o período pombalino, etc. Cada artigo, ao marcar diferentes temas, cria uma relação entre eles que pode ser lida na topografia descrita no Grafo 2. Como se pode notar, ao filtrar a rede apenas com os temas de grau igual ou superior a 5, ainda temos uma rede complexa. Assim, para revelar os temas, ou palavras-chave mais tratados na revista, produzimos um novo grafo filtrando os temas com grau igual ou superior a 20 e suas respectivas relações. 0 Grafo 3, a seguir, revela os temas mais tratados na revista, filtrados pelos novos parâmetros:

Grafo 3: Temas publicados na revista com grau igual ou superior à 20

\section{história ambiental}

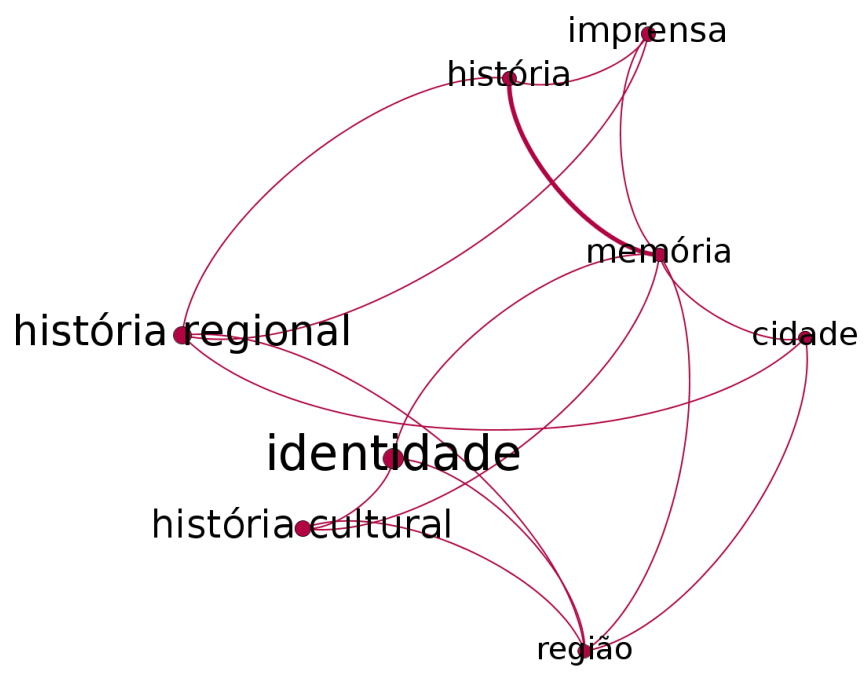


Este grafo representa as principais temáticas tratadas na revista e suas relações. Identidades culturais e seu papel na construção das regiões; os diversos aspectos relacionados às cidades; o papel da imprensa como fonte e expressão das comunidades; os diversos usos e produção das memórias e sua relação com a paisagem e com o ambiente, foram as temáticas mais exploradas pelos pesquisadores que publicaram na RHR.

\subsection{As comunidades temáticas}

Uma das metodologias comumente usadas em análise de redes, e muito útil no caso em estudo, é a detecção de comunidades. De maneira simples, e sem entrar no detalhamento técnico de caracterizar cada um dos diferentes algoritmos usados para esta tarefa, basta-nos, para os objetivos deste artigo, definir comunidade como um grupo de nós cuja interação é maior entre si do que com o conjunto da rede. Em outras palavras, e usando o vocabulário adequado ao nosso objeto de estudo, trata-se do conjunto de temas que, com mais frequência aparecem nos mesmos artigos, ou nos artigos de um mesmo autor. No nosso caso, a detecção das comunidades nos permite perceber de maneira estrutural quais os caminhos teóricos da revista e como as opções cotidianas de aprovar ou rejeitar os trabalhos apresentados se relacionam com a proposta epistemológica da RHR. Neste estudo identificamos cinco comunidades temáticas, e agrupamos as comunidades isoladas, com participação na rede inferior a dois por cento, numa sexta representação gráfica.

\subsubsection{A comunidade Região-Identidade.}

A comunidade "Região-Identidade" é, de longe, a comunidade mais significativa, com a participação de $43,06 \%$ de todas as relações expressas na rede. Participam desta comunidade 338 temas, com 1059 relações entre si. No conjunto de artigos que geraram as relações exploradas nesta comunidade são desenvolvidos estudos que, embora tenham os conceitos de região e identidade como centrais, aplicam as mais diversas abordagens em torno desses conceitos. 


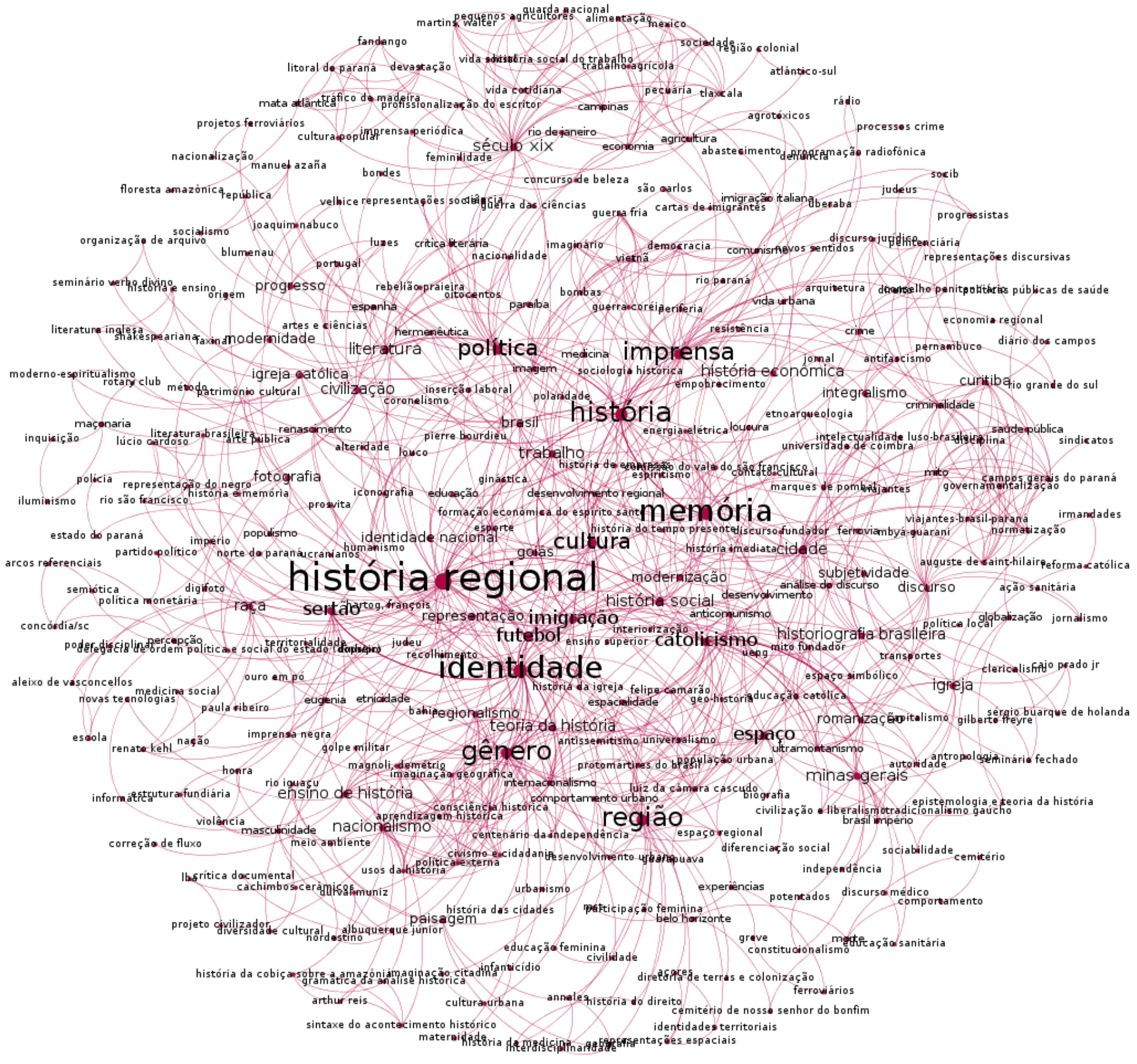


Esta comunidade temática representa $43 \%$ das relações entre os temas publicados na RHR e revela a coerência temática mantida ao longo da trajetória da revista. O conjunto dos temas relacionados produz um grafo complexo, como se observa. Para se apreender as relações centrais é necessário, então, filtrar as relações mais frequentes como faremos abaixo.

Grafo 5: Comunidade Região-Identidade com grau igual ou superior à 20

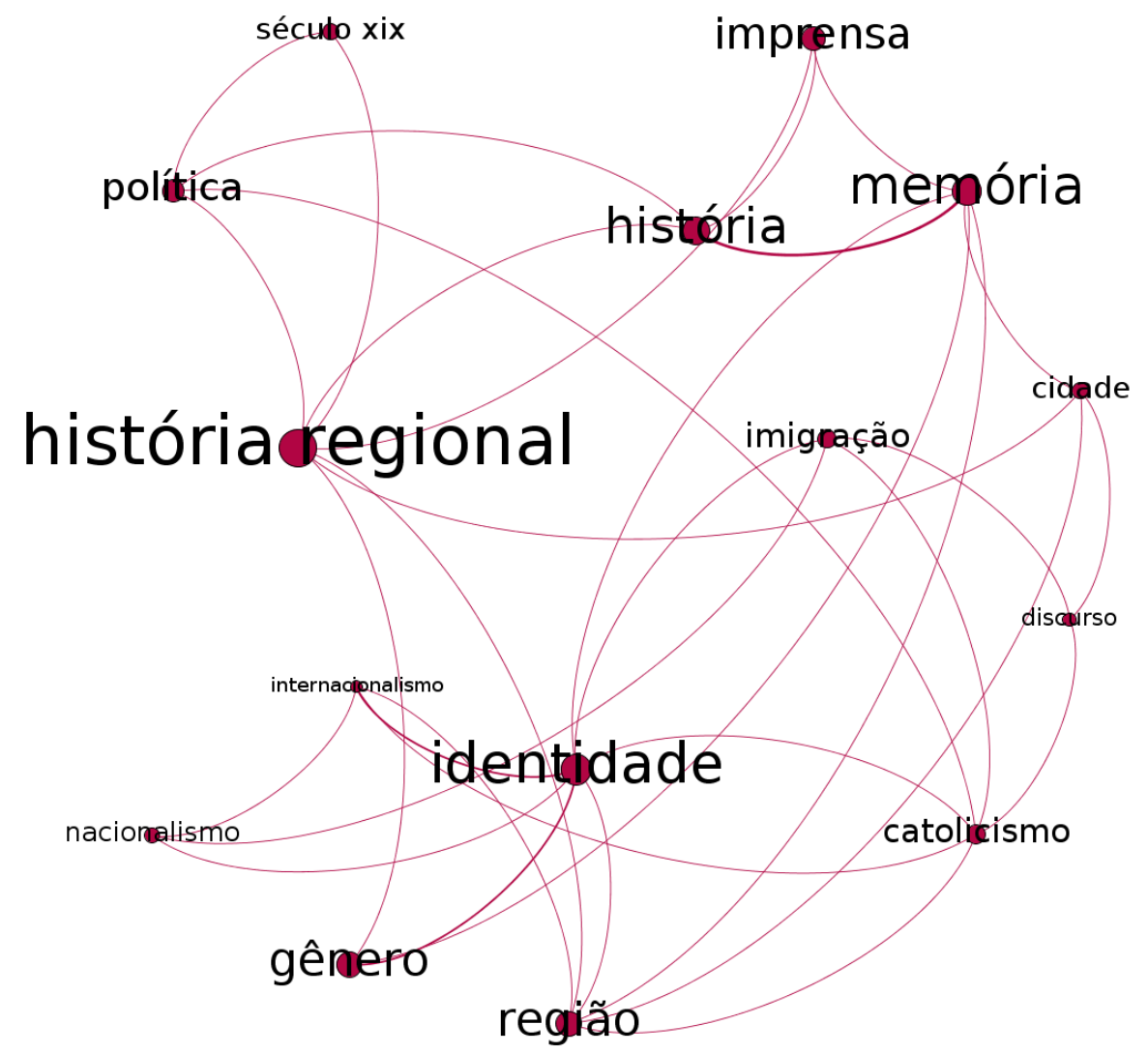

Ao aplicar um filtro com grau 20 e selecionar os temas e seus relacionamentos mais frequentes, podemos destacar as relações mais típicas exploradas nos artigos da revista nesta comunidade temática, o que nos permite destacar, com critério, alguns estudos que exemplificam os esforços dos pesquisadores 
que publicaram na RHR. Por exemplo, o debate em torno dos conceitos no qual participaram Ciro Flamarion Cardoso ${ }^{15}$, Joseli Maria Silva ${ }^{16}$, José Costa D'Assunção Barros ${ }^{17}$ e diversos outros. Para além do debate conceitual, a revista publicou um variado exercício de construção de objetos de pesquisa relacionados a estes conceitos, como o trabalho de Luiz Fernando Cerri ${ }^{18}$ sobre regionalismo e identidade no ensino de história; ou o trabalho de Dilma Andrade de Paula ${ }^{19}$, que explora as memórias da destruição da cidade de São João Marcos; o artigo de Sérgio Paulo Morais ${ }^{20}$, que explora as relações entre vida urbana e pobreza, através da imprensa; ou o trabalho de Ana Cristina Pereira Lage ${ }^{21}$ com as relações entre gênero e religiosidade ao estudar os indícios de letramento religioso na Casa de Oração do Vale de Lágrimas em Minas Gerais. Embora não seja possível, no corpo deste artigo, apresentar todas as relações temáticas decorrentes da análise efetuada, cremos que estes destaques permitem vislumbrar as relações entre as tendências teóricas dos artigos publicados e a proposta epistemológica da revista.

\subsubsection{A comunidade história cultural-ambiental.}

A segunda comunidade temática presente nas publicações da RHR está organizada em torno dos eixos temáticos da história cultural, ambiental e política. Esta comunidade representa 13,25\% das relações da rede, com 104 temas agrupados em 255 relações.

\footnotetext{
${ }^{15}$ CARDOSO, Ciro Flamarion Santana. Repensando a construção do espaço, Revista de História Regional, v. 3, n. 1, 1998.

${ }^{16}$ SILVA, Joseli Maria. Um ensaio sobre as potencialidades do uso do conceito de gênero na análise geográfica, Revista de História Regional, v. 8, n. 1, 2003.

${ }^{17}$ BARROS, José Costa D’Assunção. História, região e espacialidade, Revista de História Regional, v. 10, n. 1, 2005. ${ }^{18}$ CERRI, Luis Fernando. Regionalismo e ensino de história, Revista de História Regional, v. 1, n. 1, 1996.

${ }^{19}$ PAULA, Dilma Andrade de. Na contramão da utopia: a memória da destruição da cidade de São João Marcos, Revista de História Regional, v. 1, n. 1, 1996.

${ }^{20}$ MORAIS, Sérgio Paulo. Vida urbana, imprensa e pobreza (Uberlândia-MG 1980-2000): notas de uma pesquisa. Doi: 10.5212/Rev.Hist.Reg.v.16i2.0005, Revista de História Regional, v. 16, n. 2, 2011.

${ }^{21}$ LAGE, Ana Cristina Pereira. Vale de Lágrimas: mulheres recolhidas no sertão de Minas Gerais na segunda metade do século XVIII, Revista de História Regional, v. 19, n. 2, 2014.
} 
Grafo 6: Comunidade História Cultural-Ambiental

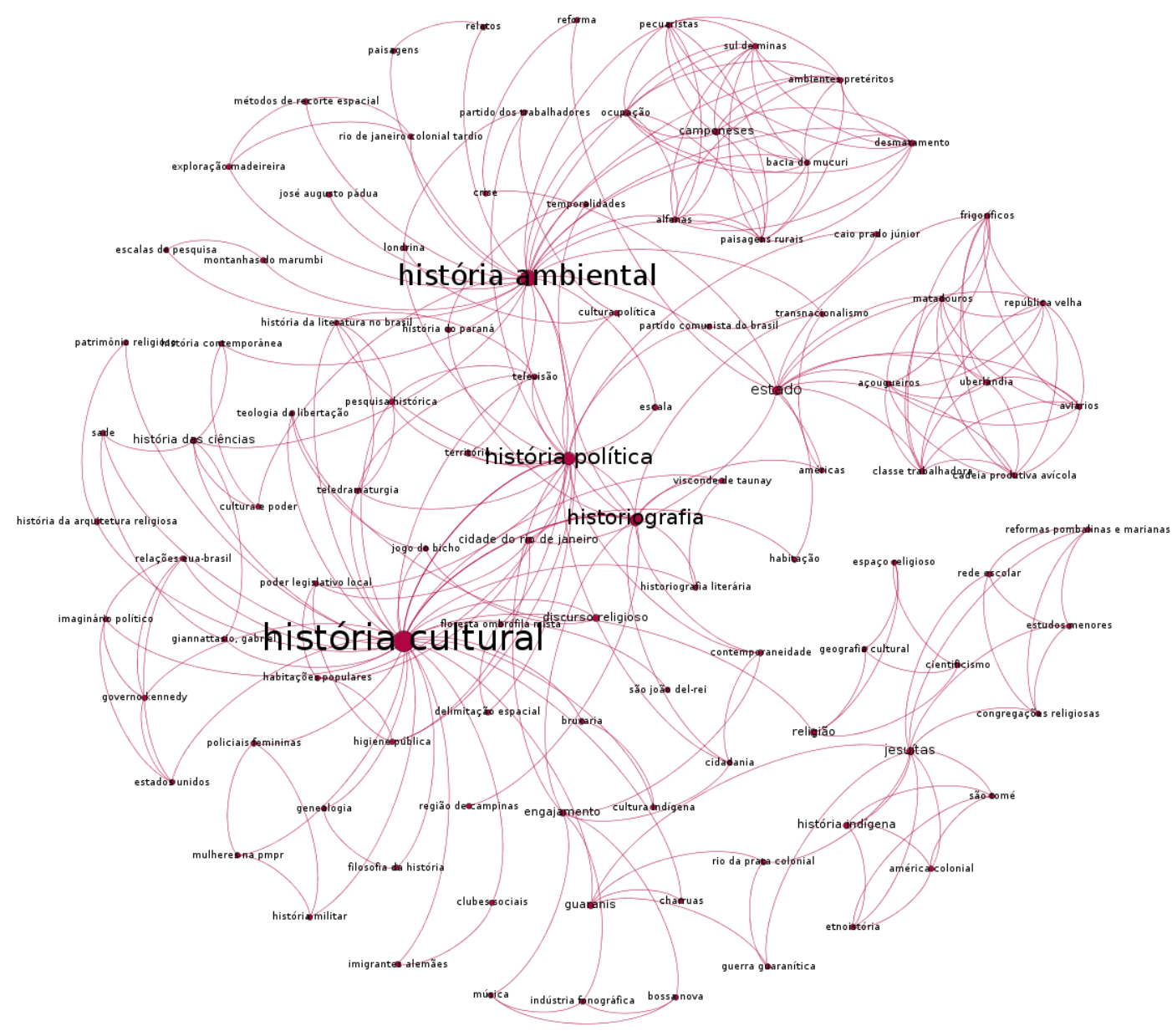

No Grafo 7, já filtrado com os temas com grau igual ou superior a 5, percebem-se os sub-conjuntos produzidos em torno dos temas relacionados à história cultural, história política e história ambiental. 0 conjunto ligado à história cultural forma o conjunto mais amplo, foram 24 artigos que colocaram diretamente a palavra-chave "história-cultural" nos seus meta-dados, e estes artigos estão distribuídos regularmente em quase todos os números da revista. Ao mesmo tempo é o conjunto que mais abre relações com outros temas. 0 sub-conjunto ligado à história ambiental é composto de 15 artigos, sendo 8 resultado de uma coletânea publicada no volume 20 da revista. $O$ sub-conjunto 
de história política com 23 artigos publicados produz uma forte ligação com os temas de "história cultural" e menos ligações com os demais.

Grafo 7: Comunidade História Cultural-Ambiental com grau igual ou superior a 5

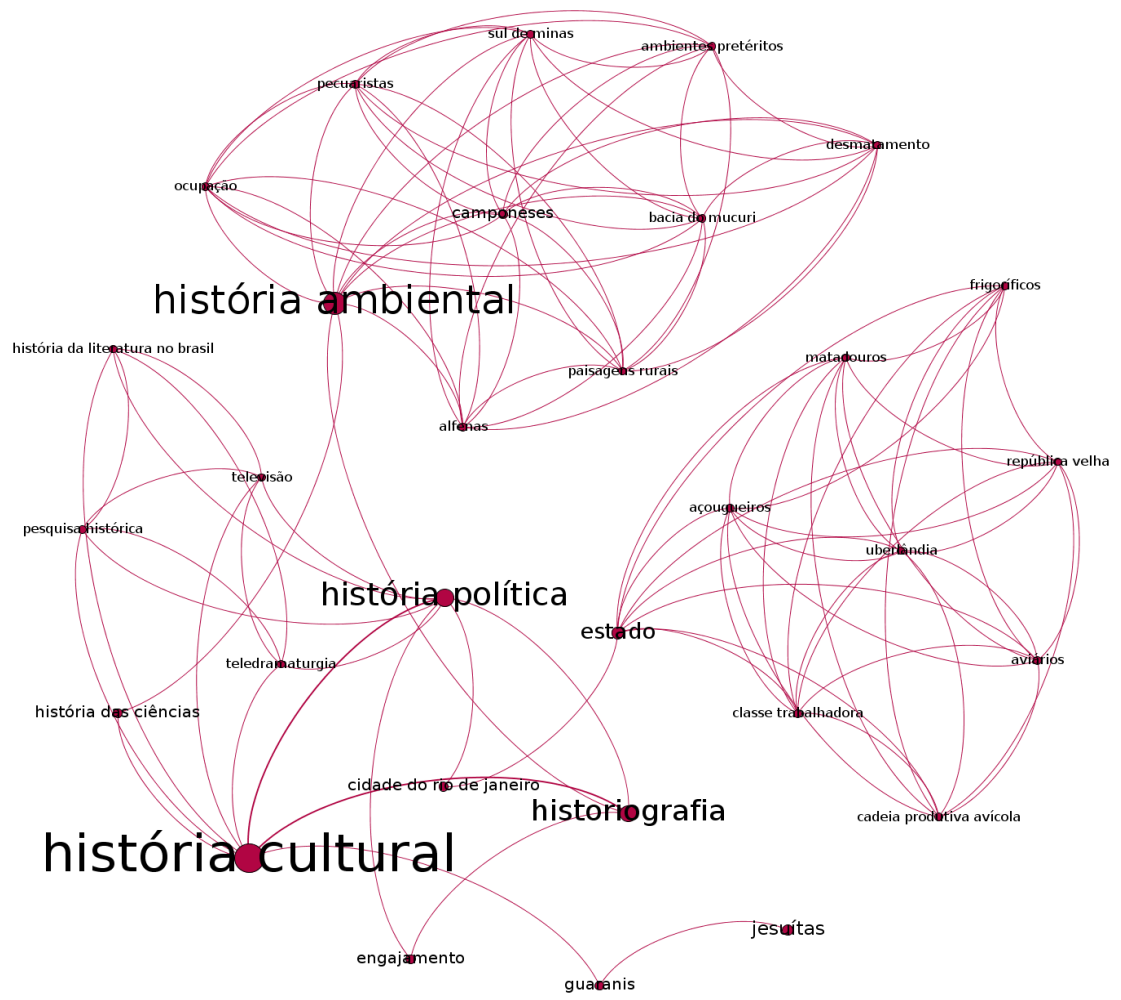

\subsubsection{A comunidade Paraná}

A terceira comunidade é composta de 9,55\% da rede, 75 temas em 191 relações. O tema articulador dessa comunidade é "Paraná". Essa comunidade expressa principalmente a produção das universidades de Maringá, Londrina e Ponta Grossa, que sempre tiveram na RHR um canal de comunicação de suas pesquisas. Trabalhadores, Reforma Agrária, Imigração, Intelectuais e Espaço Urbano são os principais aspectos aos quais o tema "Paraná" está relacionado. Esses 28 artigos se encontram distribuídos em todos os números da revista desde o primeiro número, com o artigo Semeadores Dissonantes: Imigrantes e Policiais na Província do Paraná - Século XIX, do professor Roberto Lamb ${ }^{22}$, que explora o

${ }^{22}$ LAMB, Roberto Edgar. Semeadores dissonantes: imigrantes e policiais na Província do Paraná - Século XIX, Revista de História Regional, v. 1, n. 1, 1996. 
fenômeno da imigração européia no Paraná; passando pelo texto A "Mística do Pioneirismo, Antídoto contra o Socialismo: Bento Munhoz da Rocha Neto, a Reforma Agrária e o Norte do Paraná dos anos 50 e 60", de José Henrique Rollo Gonçalves ${ }^{23}$ que representa um conjunto de artigos publicados sobre aspectos do processo de colonização do norte do Paraná; até o último número analisado neste artigo A redemocratização de 1945 no Paraná e as eleições de 1945 e 1947 de autoria de Alessandro Batistella ${ }^{24}$.

Grafo 9: Comunidade Paraná

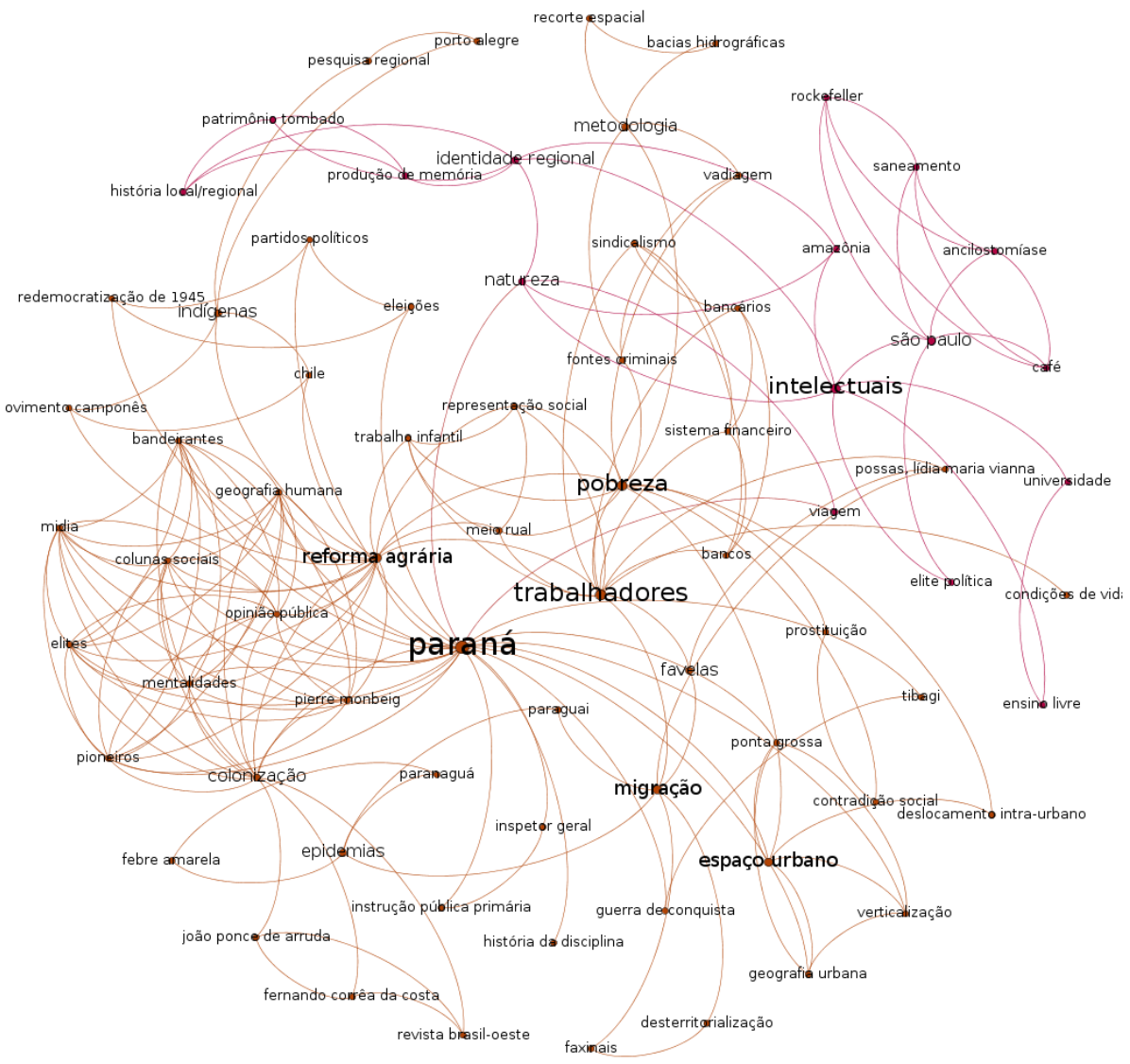

${ }^{23}$ GONÇALVES, José Henrique Rollo. A “mística do pioneirismo”, antídoto contra o socialismo: Bento Munhoz da Rocha Neto, a reforma agrária e o norte do Paraná dos anos 50 e 60, Revista de História Regional, v. 2, n. 1, 1997.

${ }^{24}$ BATISTELLA, Alessandro, A redemocratização de 1945 no Paraná e as eleições de 1945 e 1947, Revista de História Regional, v. 20, n. 2, 2015. 


\subsubsection{A comunidade "Arqueologia"}

Em torno do tema "Arqueologia" publicamos um conjunto de artigos que veicularam os resultados de pesquisa de dois grupos, um liderado pelo Professor Pedro Paulo Funari e o grupo intitulado "Tulha" que reúne professores da Universidade Estadual de Maringá, entre eles Lucio Tadeu Mota, Francisco Noelli e José Henrique Gonçalves. Do conjunto de 17 artigos publicados destacamos aqui apenas dois a título de exemplo. $\mathrm{O}$ artigo Heterogeneidade e Conflito na Interpretação do Quilombo dos Palmares, publicado pelo professor Pedro Paulo Funari ${ }^{25}$ e o texto A Guerra de Conquista nos Territórios dos Índios Kaingang do Tibagi, do professor Lúcio Tadeu Mota ${ }^{26}$, são exemplos de um conjunto de contribuições que esses grupos de pesquisa deram à revista e à historiografia brasileira.

Grafo 10: Comunidade Arqueologia

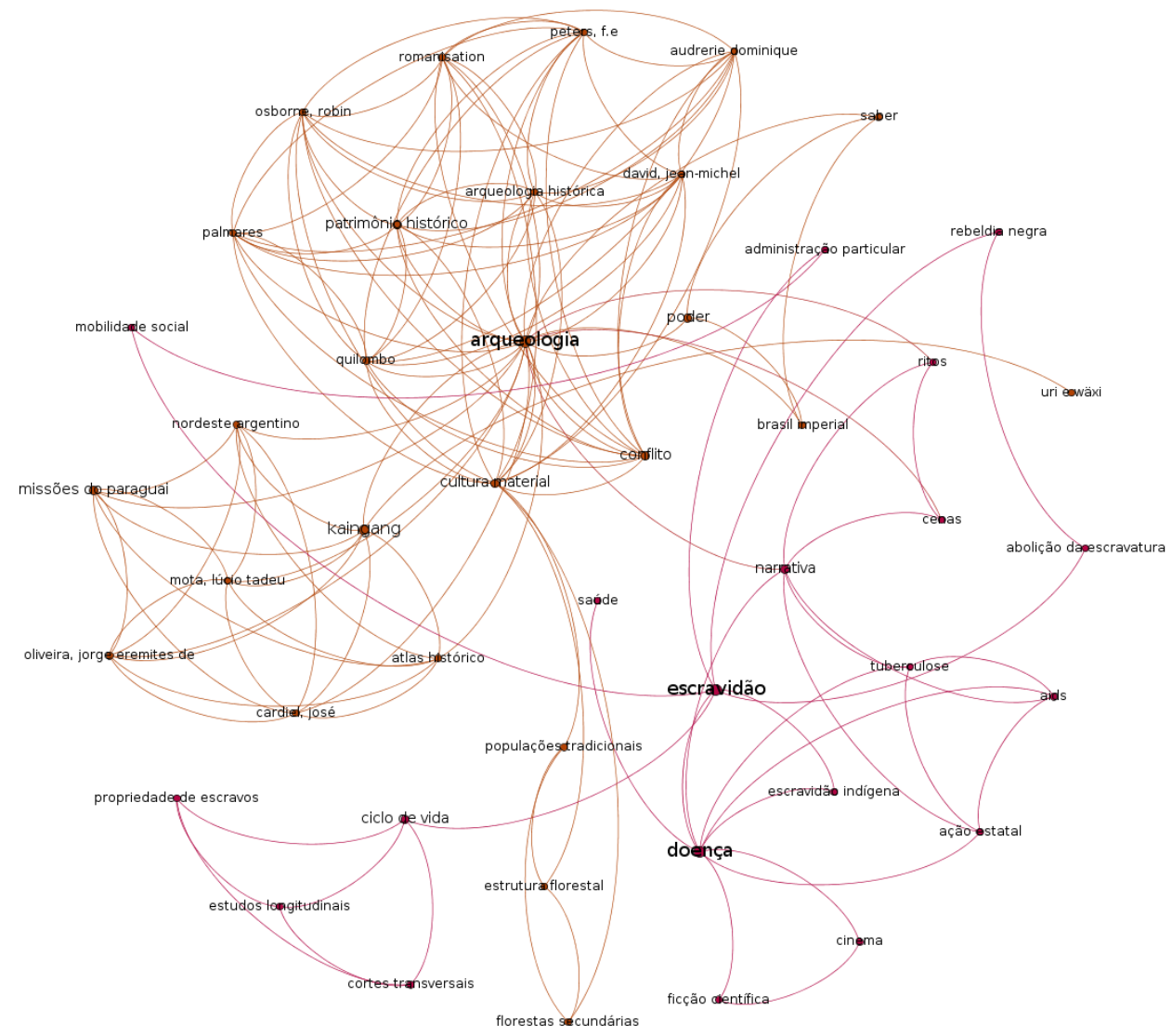

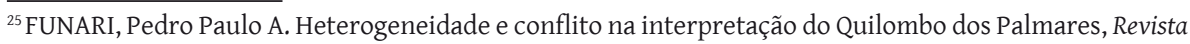
de História Regional, v. 6, n. 1, 2001.

${ }^{26}$ MOTA, Lucio Tadeu. A guerra de conquista nos territórios dos índios Kaingang do Tibagi, Revista de História Regional, v. 2, n. 1, 1997. 


\subsubsection{A comunidade História da Leitura}

Uma parte da produção apresentada na RHR, discute os vínculos entre cultura escrita (leitura, livros, bibliotecas, etc.) e as manifestações regionais dos processos contidos nessa dupla denominação. Parte-se de uma noção de cultura, mesmo que provisória, expressa como "a que articula as produções simbólicas e as experiências estéticas subtraídas às urgências do cotidiano, com as linguagens, os rituais e as condutas, graças aos quais uma comunidade vive e reflete sua relação ao mundo" 27 , que se adapta a uma noção de escrito definido como "todo e qualquer evento ou prática que tenha como mediação a palavra escrita", fazendo valer a duplicidade semântica do título entre "escrita" e "do escrito" e aprofundando a noção de que não há homogeneidade na compreensão da cultura escrita em sociedades complexas ${ }^{28}$. Esta comunidade temática, com 14 artigos pode ser exemplificada no texto Entre Leiturase Representações: Um caso de Messianismo milenarista no Norte do Paraná, de Wander de Lara Proença ${ }^{29}$ que relaciona as práticas de leitura e a eclosão do movimento, e no texto de Javier Planas ${ }^{30}$ Hacer las reglas del hacer: concepciones y rutinas bibliotecarias en los reglamentos de las bibliotecas populares en la Argentina (18701875), que demonstra como as mudanças nas regras bibliotecárias expressam um projeto pedagógico de formação de leitores na Argentina.

\footnotetext{
${ }^{27}$ CHARTIER, Roger. Escutar os mortos com os olhos, Estudos avançados, v. 24, n. 69, p. 6-30, 2010.

${ }^{28}$ GALVÃO, Ana Maria de Oliveira. História das culturas do escrito: tendências e possibilidades de pesquisa, Cultura escrita e letramento. Belo Horizonte: Editora UFMG, p. 218-248, 2010.

${ }^{29}$ PROENÇA, Wander de Lara. Entre leituras e representações: um caso de messianismo milenarista no norte do Paraná, Revista de História Regional, v. 8, n. 1, 2003.

${ }^{30}$ PLANAS, Javier, Hacer las reglas del hacer: concepciones y rutinas bibliotecarias en los reglamentos de las bibliotecas populares en la Argentina (1870-1875), Revista de História Regional, v. 19, n. 1, 2014.
} 
Grafo 11: Comunidade História da Leitura

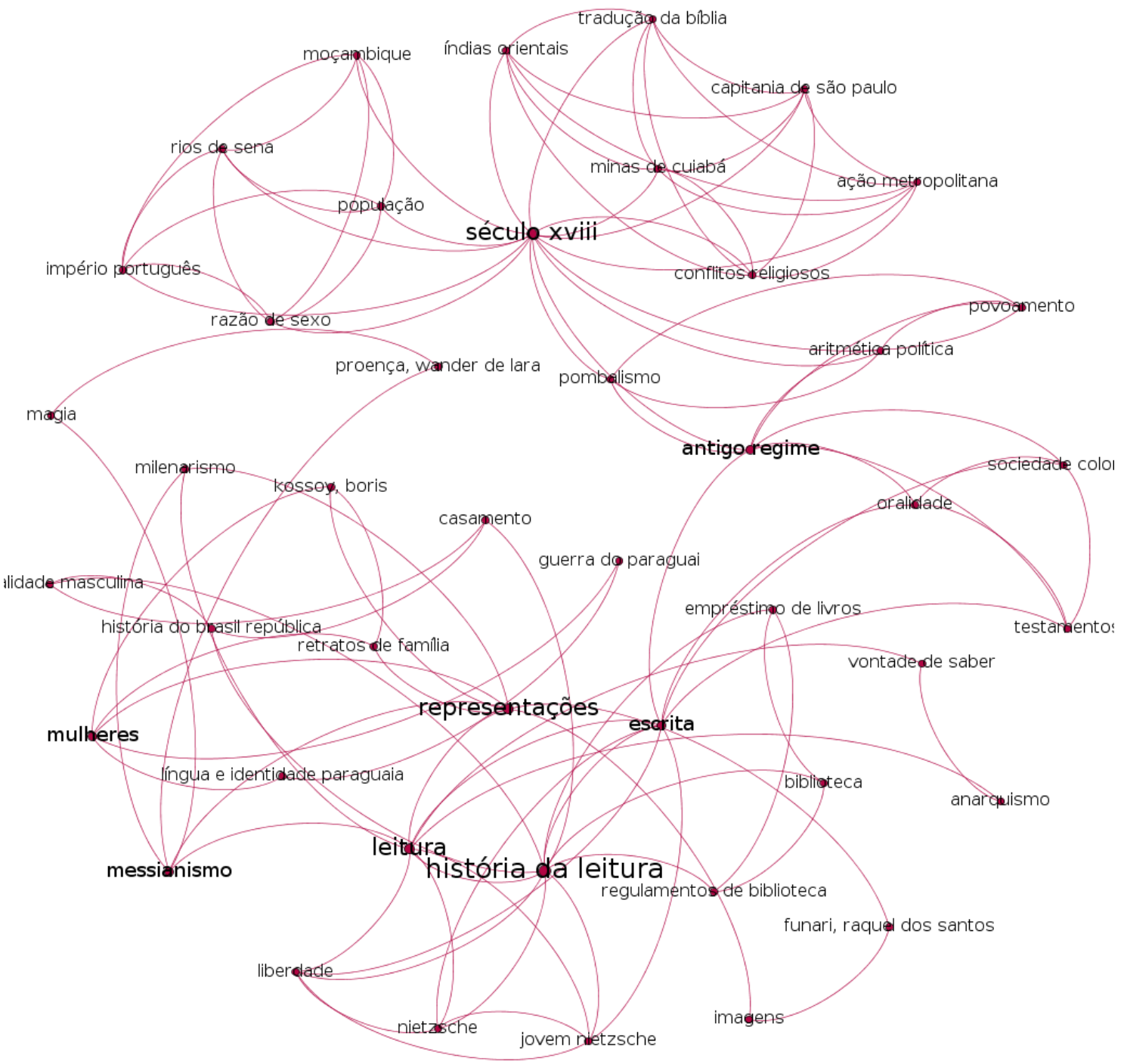

\subsubsection{As comunidades isoladas}

Finalmente, neste último grafo agrupamos todo o conjunto de comunidades isoladas, isto é, o conjunto de artigos cujos temas não geraram relações com o restante da rede. Neste grafo se revela também uma grande diversidade temática: Celso Furtado, Fronteiras, Protestantes, Ditadura Militar, etc. Cada 
sub-rede representa aqui um ou dois artigos que ao tratarem de um tema específico não geraram articulação com os demais, e portanto não produziram uma centralidade clara, mas cuja diversidade demonstra a amplitude das abordagens possíveis para a história regional.

Grafo 12: Comunidades Temáticas Isoladas

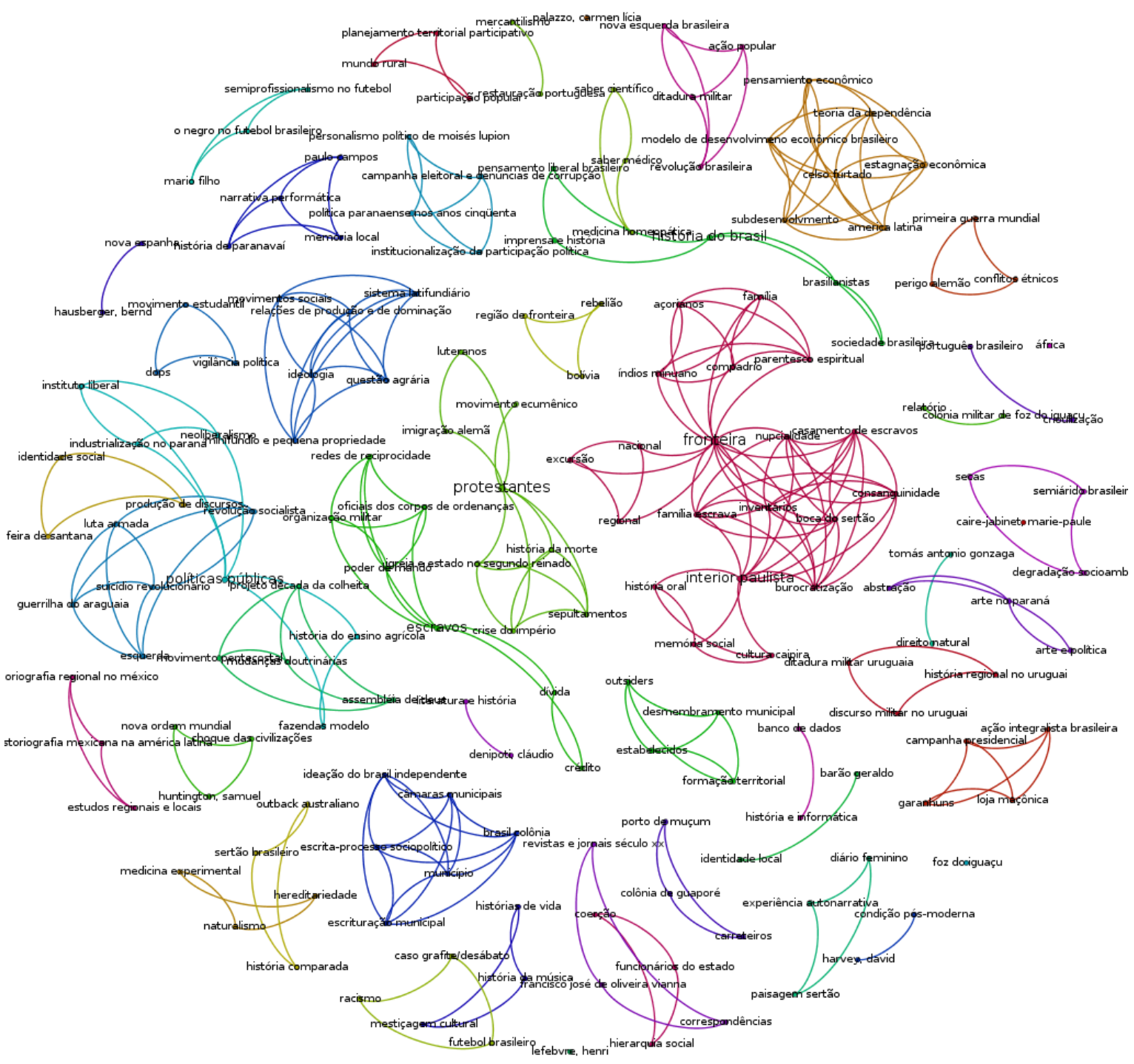




\section{As opções tecnológicas e o impacto no campo historiográfico}

Não é necessário aqui reafirmar que uma das principais funções de uma revista é a divulgação da produção científica em um campo do conhecimento. Desde o surgimento da RHR, a opção pela publicação on-line já tinha em mente o aumento do impacto da revista no campo historiográfico, diante das dificuldades da distribuição física dos exemplares em livrarias, facilitando o acesso aos pesquisadores e estudantes de história de todo o Brasil. Inicialmente, além da distribuição dos exemplares impressos para bibliotecas, permutas e outras formas de divulgação, a revista era distribuída em livrarias estratégicas, perto dos principais centros universitários. Gradativamente, porém, a versão on-line tornou-se o principal meio de divulgação da publicação.

Quando fizemos a transição do HTML básico para o sistema "OJS" (Open Journal Systems), tomamos o cuidado de tornar a revista o mais aberta possível, aderindo aos protocolos disponíveis de intercâmbio de dados, em especial ao "OAI" (Open Archives Iniciative), que promove padrões de interoperabilidade para facilitar a disseminação e acesso ao conteúdo. Essas opções, além do rigor no processo editorial, foram gradativamente aumentando o impacto da revista, tanto em razão de sua presença nos organizadores de conteúdo na internet, quanto em indexadores acadêmicos especializados.

Medir o impacto da revista no campo historiográfico brasileiro, entretanto, envolve algumas opções metodológicas. Optamos, para verificar a posicionalidade da RHR, pelas métricas do Google Scholar. Apesar dos problemas conhecidos dos sistemas quantitativos de medição de produtividade, como já observou Philip G. Altbach ${ }^{31}$, pensamos que, com as devidas ressalvas, os índices h5 e a mediana h5 nos oferecem informações que devem ser levadas em conta ao avaliar o desempenho do canal de divulgação científica.

Entre as limitações conhecidas do uso das métricas na avaliação da produtividade acadêmica estão: a desigualdade em função da comunidade linguística a que as publicações pertencem, o impacto desigual por área de conhecimento e as distorções produzidas pelos cálculos de média e mediana. Exemplificando, as revistas publicadas em inglês recebem um número significativamente maior de citações e consequentemente um índice h5 superior. Considerando-se as 100 revistas de língua inglesa melhor avaliadas, segundo esta métrica, o índice vai de 110 a 379. Entre as 100 revistas de língua portuguesa o índice começa em 12, e a publicação melhor avaliada tem o índice

\footnotetext{
${ }^{31}$ ALTBACH, Philip G. O que conta para a produtividade acadêmica nas universidades de pesquisa? - Ensino Superior Unicamp, International Higher Education, v. 79, 2015.
} 
h5 de 47. O mesmo acontece quando analisamos diferentes áreas do conhecimento. Percebemos, em relação a isso, uma evidente predominância das áreas médicas e biológicas. Por outro lado, nenhuma revista de história está ranqueada entre as 100 melhor avaliadas, nem em língua inglesa, nem nas publicações em língua portuguesa.

O índice h5 leva em consideração os últimos cinco anos e inclui, para a formação do índice, entre os artigos citados, aqueles que receberam mais citações do que o número de artigos que receberam citações. Assim, por exemplo, uma publicação que tenha cinco artigos citados com respectivamente 12, 8, 9, 3 e 2, teria um índice h5 de 3 porque foram 3 os artigos que receberam mais de 5 citações. A mediana h5 é a mediana dos artigos que foram levados em consideração no cálculo do índice. Não se trata, portanto de uma simples soma do número de citações, mas de uma composição que permite a comparação entre veículos diferentes. Este índice pode ser aplicado a instituições, revistas ou pesquisadores. Para exemplificar com um dos autores que publicaram na RHR, o autor “José D’Assunção Barros” teve, a partir de 2011, 1702 citações e obteve o h5 de "18" e a mediana h5 de "17". Isso porque 18 de seus artigos receberam mais citações do que o número de artigos citados no período e estes receberam em média 17 citações.

Definido o significado e as limitações do índice, fizemos o exercício de verificar o índice h5 e a mediana h5 em todas as 555 revistas avaliadas em 2014 pela área de história no sistema Qualis Capes a fim de verificar o posicionamento da RHR entre as revistas do campo. O impacto calculado pelas métricas do Google Scholar para a Revista de História Regional é h5 "4" e mediana h5 "6". Como não há espaço neste artigo para apresentar toda a tabela produzida, consideramos, para demonstrar a tendência, apenas as revistas do estrato A1 com impacto igual ou superior a " 4 ". 


\begin{tabular}{|c|c|c|c|c|}
\hline ISSN & REVISTA & Qualis & Índice h5 & Mediana h5 \\
\hline 0101-7330 & Educação \& Sociedade (Impresso) & A1 & 20 & 31 \\
\hline $1413-2478$ & $\begin{array}{l}\text { Revista Brasileira de Educação } \\
\text { (Impresso) }\end{array}$ & A1 & 17 & 25 \\
\hline 0011-5258 & Dados (Rio de Janeiro. Impresso) & A1 & 13 & 18 \\
\hline 0104-026X & $\begin{array}{l}\text { Revista Estudos Feministas (UFSC. } \\
\text { Impresso) }\end{array}$ & A1 & 13 & 16 \\
\hline 0104-7183 & $\begin{array}{l}\text { Horizontes Antropológicos (UFRGS. } \\
\text { Impresso) }\end{array}$ & A1 & 11 & 13 \\
\hline 0102-6909 & $\begin{array}{l}\text { Revista Brasileira de Ciências Sociais } \\
\text { (Impresso) }\end{array}$ & A1 & 11 & 16 \\
\hline 0104-5970 & $\begin{array}{l}\text { História, Ciências, Saúde-Manguinhos } \\
\text { (Impresso) }\end{array}$ & A1 & 8 & 12 \\
\hline 0102-0188 & $\begin{array}{l}\text { Revista Brasileira de História } \\
\text { (Impresso) }\end{array}$ & A1 & 6 & 7 \\
\hline $1806-9347$ & Revista Brasileira de História (Online) & A1 & 6 & 7 \\
\hline $1980-4369$ & História (São Paulo. Online) & A1 & 5 & 7 \\
\hline 0034-8309 & Revista de Historia (USP) & A1 & 5 & 6 \\
\hline $1413-7704$ & $\begin{array}{l}\text { Tempo. Revista do Departamento de } \\
\text { História da UFF }\end{array}$ & A1 & 5 & 9 \\
\hline 0103-2186 & Estudos Historicos (Rio de Janeiro) & A1 & 4 & 5 \\
\hline $1518-3319$ & Topoi (Rio de Janeiro) & A1 & 4 & 4 \\
\hline
\end{tabular}

Dois elementos se destacam da tabela acima. Em primeiro lugar, a observação que das 26 revistas alocadas no estrato A1, apenas 14 tem impacto igual ou superior a "4". Outra informação que salta aos olhos é que, apesar de avaliadas pela área de história, as revistas com maior impacto são publicações oriundas das áreas de educação ou ciências sociais, que tradicionalmente tem um impacto maior em decorrência da desigualdade de área na aplicação do índice. Não temos espaço neste trabalho para apresentar as tabelas com todos os estratos da avaliação Qualis e seu respectivo índice de impacto, mas o fenômeno se repete em todos os recortes: observa-se um índice h5 maior nas revistas oriundas de outras áreas e as revistas da própria área de história apresentam impacto entre "0" e "8". Se considerarmos apenas as revistas do campo próprio da história, a Revista de História Regional se coloca entre as 15 
revistas do campo com maior fator de impacto, oscilando, conforme o critério de inclusão na lista, entre o nono e o décimo primeiro lugar.

Pode-se afirmar que as opções tecnológicas da revista influenciaram no seu fator de impacto e também determinaram sua distribuição espacial da origem dos artigos. O cartograma abaixo mostra a origem dos trabalhos publicados pela RHR:

Mapa 1: A distribuição regional dos artigos por origem

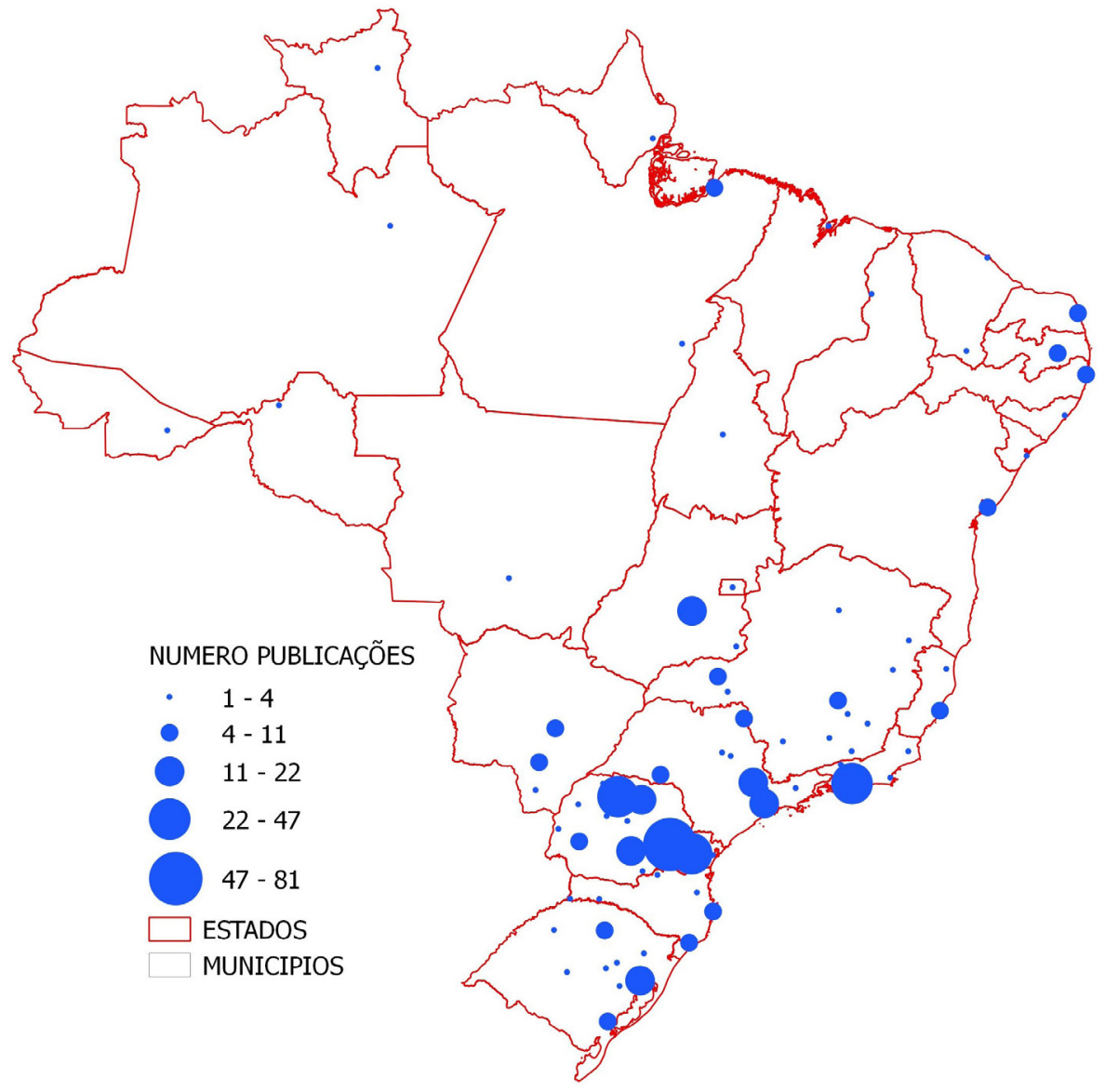

Observa-se no mapa uma concentração de artigos nas regiões sul e sudeste mas evidencia-se também a presença da produção acadêmica oriunda de todos os estados brasileiros. É perceptível aqui a penetração da RHR na maioria 
dos grandes centros de pesquisa histórica no Brasil, manifesta pela alta incidência de submissão e aceitação de trabalhos para publicação na revista.

Mapa 2: A distribuição internacional dos artigos por origem

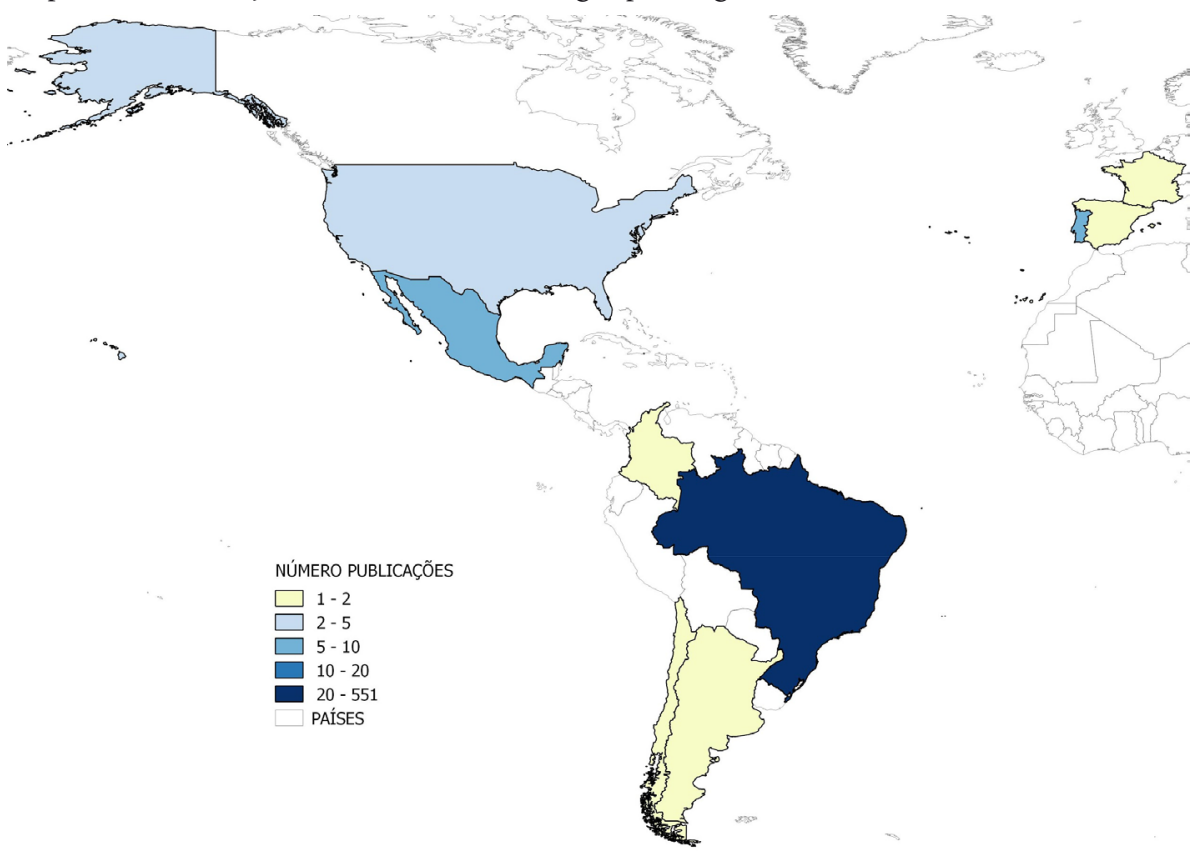

A concentração dos artigos com origem no Brasil é evidente, mas percebe-se também a presença da veiculação da produção de diversos países, em especial do México e de Portugal. Embora com incidência menor em números absolutos, fica bastante clara a relevância da penetração da RHR em países da comunidade latina das Américas do Norte e do Sul, com artigos publicados no México, Venezuela, Chile e Argentina.

\section{Apostas de desenvolvimento futuro}

Uma última ideia a destacar é que, se por um lado a RHR ganhou reconhecimento e se projetou no campo da produção do conhecimento histórico ajudando a desenvolver uma abordagem específica, por outro é necessário atentar para o fato de que o desenvolvimento tecnológico que vivemos nas últimas décadas influenciou e continuará provocando mudanças na escrita 
da história. Uma das principais características das equipes que conduziram a RHR foi justamente a atenção dispensada ao desenvolvimento tecnológico. Embora não se possa predizer os caminhos da tecnologia a equipe que conduz a RHR continuará experimentando as novas alternativas apresentadas ao fazer historiográfico. Neste momento temos desenvolvido uma plataforma que chamamos de "Memória Digital, Culturas Regionais", para a digitalização e guarda de coleções documentais. Uma das características promissoras dessa plataforma, num plugin conhecido como NEATLINE ${ }^{32}$, é a possibilidade de produção de narrativas históricas hipertextuais articuladas no tempo através de uma "time-line", e no espaço com o suporte das atuais técnicas de geoprocessamento. Não sabemos se isso irá se consolidar como uma das formas futuras de narrativa da história, mas explorar as possibilidades e os sinais que aparecem nas fronteiras do fazer histórico foi e continuará sendo um compromisso das equipes que conduzem a Revista de História Regional.

Artigo recebido para publicação em 22/11/2016

Artigo aprovado para publicação em 23/11/2016

${ }^{32}$ Neatline, disponível em: <http://neatline.org/>, acesso em: 19 nov. 2016. 